\title{
Afucosylated IgG characterizes enveloped viral responses and correlates with COVID-19 severity
}

\begin{abstract}
Mads Delbo Larsen"*, Erik L. de Graaf*, Myrthe E. Sonneveld ${ }^{1 *}$, H. Rosina Plomp ${ }^{2}$, Jan Nouta ${ }^{2}$, Willianne Hoepel ${ }^{3,4}$, Hung-Jen Chen $^{5}$,Federica Linty ${ }^{1}$, Remco Visser ${ }^{1}$, Maximilian Brinkhaus ${ }^{1}$, Tonći Šuštić ${ }^{1}$, Steven W. de Taeye ${ }^{1}$, Arthur E. H. Bentlage ${ }^{1}$, Suvi Toivonen $^{6}$, Carolien A. M. Koeleman ${ }^{2}$, Susanna Sainio ${ }^{6}$, Neeltje A. Kootstra ${ }^{7}$, Philip J.M. Brouwer ${ }^{7}$, Chiara Elisabeth Geyer ${ }^{3,4}$, Ninotska I. L. Derksen ${ }^{8}$, Gertjan Wolbink ${ }^{9}$, Menno de Winther ${ }^{5}$, Rogier W. Sanders ${ }^{7,10}$, Marit J. van Gils ${ }^{7}$, Sanne de Bruin ${ }^{11}$, Alexander P. J. Vlaar ${ }^{11}$, Amsterdam UMC COVID-19 biobank study group $\dagger$, Theo Rispens ${ }^{8}$, Jeroen den Dunnen ${ }^{3,4}$, Hans L. Zaaijer $^{12}$, Manfred Wuhrer ${ }^{2}$, C. Ellen van der Schoot ${ }^{1}$, Gestur Vidarsson ${ }^{1 *}$

'Department of Experimental Immunohematology, Sanquin Research, Amsterdam, Netherlands, and Landsteiner Laboratory, Amsterdam UMC, University of Amsterdam, Amsterdam, Netherlands. ${ }^{2}$ Center for Proteomics and Metabolomics, Leiden University Medical Center, Leiden, Netherlands. ${ }^{3}$ Department of Rheumatology and Clinical Immunology, Amsterdam UMC, Amsterdam Rheumatology and Immunology Center, Amsterdam, Netherlands. ${ }^{4}$ Department of Experimental Immunology, Amsterdam UMC, University of Amsterdam, Amsterdam, Netherlands. ${ }^{5}$ Department of Medical Biochemistry, Experimental Vascular Biology, Amsterdam UMC, Cardiovascular Sciences, Amsterdam Infection and Immunity Institute, University of Amsterdam, Amsterdam, Netherlands. ${ }^{6}$ Finnish Red Cross Blood Service, Helsinki, Finland. ${ }^{7}$ Department of Medical Microbiology, Amsterdam UMC, Amsterdam Infection and Immunity Institute, University of Amsterdam, Amsterdam, Netherlands. ${ }^{8}$ Department of Immunopathology, Sanquin Research, Amsterdam, Netherlands, and Landsteiner Laboratory, Amsterdam UMC, University of Amsterdam, Amsterdam, Netherlands. ${ }^{9}$ Amsterdam Rheumatology and Immunology Center, Reade, Amsterdam, Netherlands. ${ }^{10}$ Weill Medical College of Cornell University, New York, USA. ${ }^{11}$ Department of Intensive Care Medicine, Amsterdam UMC (Location AMC), University of Amsterdam, Amsterdam, Netherlands. ${ }^{22}$ Department of Blood-borne Infections, Sanquin, Amsterdam, Netherlands.
\end{abstract}

*These authors contributed equally to this work.

†Amsterdam UMC COVID-19 biobank study group collaborators and affiliations are listed in the supplementary materials.

†Corresponding author. Email: g.vidarsson@sanquin.nl

lgG antibodies are crucial for protection against invading pathogens. A highly conserved $\mathbf{N}$-linked glycan within the IgG-Fc tail, essential for IgG function, shows variable composition in humans. Afucosylated IgG variants are already used in anti-cancer therapeutic antibodies for their elevated activity through Fc receptors (FcyRIIla). Here, we report that afucosylated IgG ( $6 \%$ of total IgG in humans) are specifically formed against enveloped viruses but generally not against other antigens. This mediates stronger FcyRIIIa responses, but also amplifies brewing cytokine storms and immune-mediated pathologies. Critically ill COVID-19 patients, but not those with mild symptoms, had high levels of afucosylated IgG antibodies against SARS-CoV-2, amplifying pro-inflammatory cytokine release and acute phase responses. Thus, antibody glycosylation plays a critical role in immune responses to enveloped viruses, including COVID-19.

Antibody function has long been considered static and mostly determined by their isotype and subclass. The presence of a conserved N-linked glycan at position 297 in the $\mathrm{Fc}$ domain of IgG, is essential for its effector functions (1-3). Moreover the composition of this glycan is highly variable, which has functional consequences (2-4). This is especially true for the core fucose attached to the Fc glycan. The discovery that IgG variants without core fucosylation cause elevated antibodydependent cellular cytotoxicity (ADCC), via increased IgG-Fc receptor IIIa (Fc $\gamma$ RIIIa) affinity $(5,6)$, has resulted in nextgeneration glyco-engineered monoclonal antibodies $(\mathrm{mAb})$ lacking core fucosylation for targeting tumors (7).

Generally, changes in the Fc glycans are associated with age, sex, and autoimmune diseases, and are most pronounced for IgG-Fc galactosylation, which decreases steadily with advancing age. After a marked elevation in young women, IgG-Fc galactosylation decreases during menopause to the levels seen in men (8). IgG-Fc fucosylation is more stable, decreasing slightly from birth to approximately $94 \%$ at adulthood (9), after which it remains fairly constant, albeit with a minor reduction throughout life $(8,10)$.

Despite the apparent constant level of Fc fucosylation during adulthood, alloantibodies against red blood cells (RBCs) and platelets show remarkably low IgG-Fc fucosylation in most patients, even down to $10 \%$ in several cases (11-13). By contrast, overall serum IgG-Fc fucosylation is consistently high. Moreover, lowered IgG-Fc fucosylation is one of the factors determining disease severity in pregnancy-associated alloimmunizations, resulting in excessive thrombocytopenia and $\mathrm{RBC}$ destruction when targeted by afucosylated 
antibodies (12-14). In addition to the specific afucosylated IgG response against platelets and $\mathrm{RBC}$ antigens, this response has only been identified against HIV and dengue virus $(15,16)$. Interestingly, low core fucosylation of anti-HIV antibodies has been suggested to be a feature of elite controllers of infection, whereas for dengue, it has been associated with enhanced pathology due to excessive Fc $\gamma$ RIIIa activation (15, 16). The mechanisms controlling IgG core fucosylation remain unclear however.

Similar afucosylated IgG are found in various alloimmune responses (11-13, 17), HIV (16) and dengue (15), which are all directed against surface-exposed, membrane-embedded proteins. Therefore, we analyzed IgG glycosylation in anti-human platelet responses and in natural infections by enveloped viruses, including human immunodeficiency virus (HIV), cytomegalovirus (CMV), measles virus, mumps virus, hepatitis B virus (HBV), and severe acute respiratory syndrome coronavirus 2 (SARS-CoV-2). We also assessed responses to a non-enveloped virus (parvovirus B19), vaccination with a HBV-protein subunit, and live attenuated enveloped viruses, to test if the antigen context was an important determinant for IgG-Fc glycosylation.

IgG-Fc glycosylation of affinity-purified total and antigenspecific antibodies were made possible by tandem liquid chromatography-mass spectrometry (LC-MS) (Fig. 1 and fig. S1) $(12,17,18)$. Fc fucosylation of antigen-specific antibodies against the alloantigen human platelet antigen (HPA)-1a were substantially reduced (14) (Fig. 2A), akin to previous findings for other alloantigens $(12,17)$. Analogous to platelet and $\mathrm{RBC}$ alloantigens $(11-13,17)$, the response to the enveloped viruses CMV and HIV also showed significant afucosylation of the antigen-specific IgG (Fig. 2B). By contrast, IgG against the non-enveloped virus parvovirus B19 were fucosylated (Fig. 2C). Notably, the total IgG showed high fucosylation levels throughout (Fig. 2, A to C), reaffirming previous findings that the majority of IgG responses result in fucosylated $\operatorname{IgG}(12,18,19)$. The extent of afucosylated IgG responses to the enveloped viruses was highly variable, both between individuals and between the types of antigen, similar to observations of immune responses to different RBC alloantigens (17). Afucosylation was particularly strong for CMV and less pronounced for HIV (Fig. 2B), confirming previous observation in HIV (16). Afucosylated IgG-responses were often accompanied by elevated galactosylation (fig. S2).

To test whether some individuals had a greater intrinsic capacity to generate an afucosylated IgG response than others, we compared IgG1-Fc fucosylation levels against two different antigens within the same individual. No correlation was observed comparing the level of afucosylation between two different antigens within the same individual, neither for anti-HPA-la and anti-CMV (fig. S3A), nor for anti-HIV and anti-CMV antibodies (fig. S3B). Thus, the level of afucosylation is not pre-determined by general host factors such as genetics but is rather stochastic or multifactorial, with the specific triggers remaining obscure.

To further investigate the immunological context by which potent afucosylated IgG is formed, we compared immune responses to identical viral antigens in different contexts. First, we compared hepatitis B surface antigen (HBsAg)-specific antibody glycosylation in humans naturally infected with $\mathrm{HBV}$ or vaccinated with the recombinant HBsAg protein (Fig. 2D). Total IgG1-Fc fucosylation levels were similar for the two groups, whereas anti-HBsAg IgG1-Fc fucosylation was elevated in individuals vaccinated with the HBsAg protein when compared to either total IgG- or antigen-specific IgG-Fc fucosylation of the naturally infected group (Fig. 2D). Thus, HBsAg-specific antibodies in individuals who cleared a natural infection show lowered Fc fucosylation compared to protein subunit vaccination. This strongly suggests that a specific context for the antigenic stimulus is required for afucosylated IgG responses.

We then compared antiviral IgG responses against mumps and measles viruses formed after a natural infection or vaccination with live attenuated viruses. Unlike the HBV protein subunit vaccine, both live attenuated vaccines showed a similar antigen-specific Fc fucosylation compared to their natural infection counterpart (Fig. 2E and fig. S4). The tendency to generate afucosylated IgG was weak for measles, whereas the mumps response showed clear signs of afucosylation by either route of immunization (Fig. 2E and figs. S4 and S5).

We then tested if this type of response also plays a role in patients with coronavirus disease 2019 (COVID-19). Symptoms of COVID-19 are highly diverse, ranging from asymptomatic or mild self-limiting infection to a severe airway inflammation leading to acute respiratory distress syndrome (ARDS), often with a fatal outcome $(20,21)$. Both extreme trajectories follow similar initial responses: patients have approximately a week of relatively mild symptoms, followed by a second wave that either resolves the disease or leads to a highly aggravated life-threatening phenotype $(20,21)$. Both the timing of either response type and the differential clinical outcome suggested different routes taken by the immune system to combat the disease. So far, no clear evidence has emerged that can distinguish between these two hypothetical immunological paths. In accordance with our hypothesis and responses observed against other enveloped viruses, anti-S IgG responses against SARS-CoV-2 spike protein (S), which is expressed on the cell surface and the viral envelope, were strongly skewed toward low levels of core fucosylation. By contrast, responses against the nucleocapsid protein $(\mathrm{N})$, which is not expressed on cell surface/viral envelope, were characterized by high levels of fucosylation (Fig. 3A). The IgG response appeared to be highly specific for SARS-CoV-2 as 
there was very weak or absent reactivity to SARS-CoV-2 antigens in pre-outbreak samples, even to the more conserved $\mathrm{N}$ antigen (fig. S6) (22). Importantly, the anti-S IgG1 responses of patients with ARDS recently hospitalized in intensive care units ( $<5$ days) were significantly less fucosylated than in convalescent plasma donors consisting of individuals who were asymptomatic or had relative mild symptoms (nonARDS) (Fig. 3A).

These decreased levels of Fc fucosylation of anti-S IgG were not a result of inflammation as total IgG-Fc fucosylation levels were similar between the two groups and to what has been reported in the general population $(\sim 94 \%)(12,18)$. In addition, IgG1-Fc galactosylation and sialylation of both anti$\mathrm{S}$ and anti-N responses (Fig. 3, B and C) were significantly increased compared to total IgG, consistent with reports describing increased Fc galactosylation and sialylation in active or recent immunization $(18,23)$. Total IgG1-Fc galactosylation and sialylation levels were significantly lowered in the ARDS patients, which was perhaps a reflection of a slight age difference between these two groups [non-ARDS donors median age (IQR) 49 (40 to 55) years versus ARDS patients 60 (55-63) years (tables S1 and S2)]. Notably, both Fc galactosylation and sialylation decrease with age $(9,19)$. Increased galactosylation and sialylation of antigen-specific IgG1-Fc elevates complement activity by approximately three- to fourfold. Fc galactosylation further enhances affinity of afucosylated IgG to Fc $\gamma$ RIII by approximately twofold (24). Lastly, although Fc bisection was significantly lowered in both anti$\mathrm{N}$ and anti-S responses (Fig. 3D), the biological and clinical significance of this is limited as IgG-Fc bisection affects neither Fc receptor nor complement activity (24). More importantly, accumulating evidence strongly suggests that the primary and major biologically relevant change in IgG-Fc glycosylation is the lack of core fucose. Afucosylated IgG have a 20-40-fold increase in affinity to FcrRIIIa, often accompanied by an absolute change from no cellular response to strong phagocytic and ADCC responses upon afucosylation $(5,15,24,25)$. The lowered Fc fucosylation in the anti-S responses of the ARDS patients suggests a pathological role through Fc $\curlyvee$ RIIIa, similar to what has previously been proposed for dengue (15). In dengue, non-neutralizing antibodies formed to previous infections of other dengue serotypes also tend to have low levels of core-fucosylated IgG. As they are incapable of preventing infection, they lead to aggravated dengue hemorrhagic fever due to Fc $\gamma$ RIIIa-mediated overreactions by immune cells (15).

ARDS patients were sampled within 1 week after ICU admission and non-ARDS patients were convalescent non-hospitalized individuals. In order to eliminate any possible sampling bias in the observed IgG-Fc glycosylation patterns over time, we also analyzed longitudinal samples from both groups (26). Alloantibody Fc fucosylation to platelets and
$\mathrm{RBC}$ antigens is stable for at least a decade with or without natural booster through pregnancies $(12,14)$ or blood transfusion (27). This also held true for anti-CMV and anti-HIV responses (fig. S7). By contrast, changes in all glycosylation traits were already observed for SARS-CoV-2 during the first week following ICU admission (Fig. 3, E to L and figs. S8 and S9). These observed changes in Fc galactosylation (fig. S8) were in line with previous reports that recent immunizations are accompanied with a transient rise in antigen-specific IgGFc galactosylation and sialylation $(18,23)$. After seroconversion, all ARDS patients initially showed low levels of anti-S IgG fucosylation compared to non-ARDS patients. Fucosylation levels rose over time in ARDS patients, reaching levels comparable to those of the non-ARDS cohort (Fig. 3, E and $\mathrm{G})$. The increases in fucose levels were associated with simultaneous rises in IgG levels (Fig. 3, E to H, and fig. S10, A and $\mathrm{B})$, which were much less pronounced in the non-ARDS cohort. Similar kinetics were observed for anti-N IgG levels (Fig. 3 , J and L). Reduced levels of anti-N Fc fucosylation were also present in the ARDS group, although to a lesser degree than for anti-S (Fig. 3, I and $\mathrm{K}$ and fig. S11). This unexpected reduction in the fucosylation of anti-N IgG seen in the ARDS cohort may have been the result of classical bystander effects (28). Namely, B cells proliferating in the same lymphoid organs receive similar environmental cues from antigen-presenting cells and T cells. The IgG1-Fc fucosylation of anti-S and anti-N correlated significantly (Fig. 3M) with higher levels of afucosylation for anti-S $(P<0.0001)$. Significant correlations were also observed for other glycosylation traits, with similar skewing for both anti-S and anti-N IgG (fig. S12). These elevations in antigen-specific IgG1-Fc galactosylation and sialylation agreed with earlier reports suggesting that these are general features of newly formed ongoing immune responses $(18,23)$. Total IgG1-Fc fucosylation remained stable throughout the observation period (figs. S8J and S9J).

We then asked how these afucosylated anti-SARS-CoV-2 antibodies might contribute to the strong inflammatory response observed in ARDS patients. Alveolar macrophages are front-line scavengers in the lung and express Fc $\gamma$ RIIIa, the major myeloid sensory receptor for afucosylated IgG. Thus, we examined their potential to stimulate the production of the pro-inflammatory cytokine interleukin (IL)-6, the cytokine that is most critical for acute-phase responses in humans (29). Afucosylated IgG, together with Toll-like receptor (TLR)3 ligand, enhanced IL-6 production from macrophages in vitro, particularly when using afucosylated and highly galactosylated IgG, as is found prominently in the ARDS patients (Fig. 3N and figs. S8 and S13). There was a significant correlation between anti-S IgG1-Fc fucosylation and both plasma IL-6 and C-reactive protein (CRP) levels (Fig. 3, O and $\mathrm{P})$. This agrees with our hypothesis that afucosylated antiSARS-CoV-2 IgG plays an important role in COVID-19 
pathogenesis. Levels of plasma IL-6 and CRP increased around the time when afucosylated anti-S IgG appeared, which suggested a direct causality (Fig. 4, A and B). Plasma D-dimer levels also shared this temporal pattern (fig. S14). Thus, the afucosylated and highly galactosylated anti-S and anti-N IgG in some patients may cause an exaggerated release of pro-inflammatory cytokines and subsequent systemic inflammation due to their enhanced binding capacity to Fc $\gamma R I I I a(24)$ on alveolar macrophages. No increase of either IL-6 or CRP was observed in the non-ARDS cases (Fig. 4, C and $\mathrm{D}$, and fig. S15).

In conclusion, our results show a pattern of afucosylated IgG1 immune responses against membrane-embedded antigens such as surface membrane proteins of allo-antigens on blood cells or on enveloped viruses (including attenuated enveloped virus vaccines that often complete their first round of infection). This contrasts with soluble protein antigens and non-enveloped viruses for which immune responses with high levels of IgG1-Fc fucosylation were consistently observed. Although there was afucosylated anti-N IgG in COVID-19 patients, this was no longer the case 1-2 weeks after seroconversion.

We hypothesize that antigen-presenting membranes are directly sensed by B cells by combining at least two signals provided by the B cell receptor and undescribed host receptor-ligand pair(s). This two-step mechanism would be essential for the production of long-lasting afucosylated IgG responses and would not be triggered by soluble proteins, internal proteins of enveloped viruses, or non-enveloped viruses (Fig. 5). Alternatively, differential antigen recognition may be more complex and require additional interactions from antigen-presenting cells, T cells, and/or cytokines. This notion is supported by the fact that anti-N SARS-CoV-2 responses occur concomitantly with anti-S responses, which suggests that proximal factors in the lymphoid microenvironment can influence the response.

This work suggests that providing foreign B cell antigens in the context of the host-cell membrane may be necessary but not sufficient to trigger an immune response with high levels of long-lasting afucosylated IgG (17). This translates into varied Fc fucosylation levels between individuals as well as for distinct responses of the same individual against different antigens. The large difference in the level of antigenspecific afucosylated responses observed between patients contributes to the variability of disease severity, as has been shown for neonatal alloimmune cytopenias $(12,13,17)$ and dengue (15). Here, we also show its importance for the pathogenesis of COVID-19. Thus, afucosylation may potentially help predict disease trajectories and guide future treatments aimed at minimizing this Fc $\gamma$ RIIIa stimulus.

Importantly, IgG-Fc afucosylation results in potent immune responses. Namely, Fc $\curlyvee$ RIIIa-expressing NK cells, monocytes, and macrophages as well as Fc $\curlyvee$ RIIIb-expressing granulocytes are triggered to destroy target cells. This response may be desirable in some responses, such as against HIV (16), and can be achieved with available attenuated enveloped viral vaccine shuttles (30) against targets for which vaccine-based approaches have failed. However, this phenomenon can also lead to an undesirable exaggerated response, as is the case for both dengue virus (15) and SARS$\mathrm{CoV}-2$. Attenuated virus vaccine ferrying spike proteins of SARS-CoV are known to produce strong antibody-dependent enhanced responses (31) mimicking pathologies in critically ill SARS-CoV-2 patients (21). This suggests subunit protein vaccines may be a safer option as seen in rat models for SARSCoV-2 (32), unless the vaccine also induces a strong neutralizing effect that can thereby contribute to enhanced protection.

The afucosylation of anti-S IgG may contribute to the exacerbation of COVID-19 in a subset of patients resulting in ARDS. Thus, although they can be protective, antibodies potentially behave as double-edged swords and may contribute to the observed cytokine storm (33). As such, this has direct consequences for the development of improved IVIg, convalescent plasma, and vaccine therapies. In addition, the suggested role of afucosylated antibodies in the pathogenesis of SARS-CoV-2 may open up additional opportunities for the treatment of COVID-19. Thus, attempts to generate high-titer immunoglobulin treatments should preferably use plasma enriched in fucosylated anti-SARS-CoV-2 antibodies. This may avoid the escalation of symptoms and promote virus neutralization in patients preferentially before developing afucosylated IgG responses.

\section{Materials and Methods Patient samples}

Healthy blood donor samples from Sanquin, Amsterdam, The Netherlands, were used to analyze parvovirus B19 $(n=$ 22 ), measles virus ( $n=24$ natural infection, $n=21$ live-attenuated vaccine), mumps virus ( $n=24$ natural infection, $n=21$ live-attenuated vaccine), and HBV antibodies ( $n=17$ natural infection, $n=17$ HBsAg vaccination). Anti-HPA-1a samples have been described elsewhere (14). HIV-samples $(n=80)$ from the Amsterdam Cohort Studies on HIV infection and AIDS (ACS) were used to analyze HIV-specific antibody glycosylation. Peripheral blood samples used to purify CMVspecific antibodies $(n=102)$ were from same cohort as used for HPA-1a collected by the Finnish Red Cross Blood service, Platelet Immunology Laboratory, Helsinki, Finland and the HIV cohort described above. SARS-CoV-2 patient samples from ICU patients from the Amsterdam UMC COVID study group were included, as well as Sanquin blood donors found seropositive for SARS-CoV-2, and mild longitudinal samples from hospital workers monitored after potential exposure 
(26). A summary of the patients demographics is found in table S1, and detailed patient treatments of the ARDS COVID19 patients in table S2 (all requiring ventilation). The ACS have been conducted in accordance with the ethical principles set out in the declaration of Helsinki and all participants provided written informed consent. The study was approved by the Academic Medical Center institutional Medical Ethics Committee of the University of Amsterdam.

\section{Purification of CMV-specific antibodies from sera}

CMV-specific antibodies were purified using antigencoated plates (Serion ELISA classic, Cytomegalovirus IgG, Würzburg, Germany). Sera ( $20 \mu \mathrm{l})$ were diluted in specimen diluent $(80 \mu \mathrm{l})$ from the kit and then incubated in the plates for 1 hour at $37^{\circ} \mathrm{C}$. Positive and negative controls from the kit and CMV-negative patients samples were used as controls. The plates were washed three times with wash buffer (300 $\mu l)$ from the kit, twice with phosphate buffered saline (PBS) $(300 \mu \mathrm{l})$, and twice with deionized water $(300 \mu \mathrm{l})$. The bound antibodies were then eluted with $100 \mu \mathrm{l}$ of $100 \mathrm{mM}$ formic acid. No IgG was found in eluates from blank wells and CMVnegative patient samples.

\section{Purification of measles- and mumps-virus-specific antibodies from sera}

$\mathrm{Ag}$-specific antibodies were purified using antigen-coated plates (Serion ELISA classic, Measles IgG and Mumps IgG, Würzburg, Germany). Sera $(20 \mu \mathrm{l})$ were diluted in specimen diluent $(80 \mu \mathrm{l})$ from the kit and then incubated in the plates for 1 hour at $37^{\circ} \mathrm{C}$. Positive and negative controls from the kit were used. The plates were washed three times with wash buffer $(300 \mu \mathrm{l})$ from the kit, twice with PBS $(300 \mu \mathrm{l})$, and twice $50 \mathrm{mM}$ ammonium bicarbonate $(300 \mu \mathrm{l})$. The bound antibodies were then eluted with $100 \mu \mathrm{l}$ of $100 \mathrm{mM}$ formic acid. IgG was found in the eluates of positive controls and no IgG was found in eluates from blank wells and negative control samples.

\section{Purification of $H B V$-specific antibodies from sera}

To isolate HBsAg specific antibodies from patients after infection and vaccination, $\mathrm{HB}$ antigen-coated plates (ETI-ABAUK-3, Diasorin, Schiphol-Rijk, The Netherlands) were used. Sera $(20 \mu \mathrm{l})$ were diluted in specimen diluent $(80 \mu \mathrm{l})$ from the kit and then incubated in the plates for 1 hour at room temperature (RT) with shaking. HBV-naive and HBV-resolved samples from Sanquin, Amsterdam, The Netherlands were used as controls. Washing and elution of specific antibodies was performed as described above for CMV-specific antibodies.

First release: 23 December 2020

\section{Purification of $\mathrm{HIV}$-specific antibodies from sera}

HIV-specific antibodies were isolated using HIV antigencoated plates (Murex HIV1.2.0 kit 9E25-01, Diasorin, Schiphol-Rijk, The Netherlands). Sera were diluted $(50 \mu \mathrm{l})$ were diluted in specimen diluent $(50 \mu \mathrm{l})$ from the kit and then incubated in the plates for 1 hour at room temperature (RT) with shaking. As a positive control, anti-HIV gp120 monoclonal was used (IgG1 b12; $100 \mu \mathrm{g}$ of purified antibody in PBS at $1 \mathrm{mg} / \mathrm{ml}$; NIH Aids Reagent Program, La Jolla, CA, US). Washing and elution of specific antibodies was performed as described above for CMV-specific antibodies.

\section{Purification of parvovirus B19-specific antibodies from sera}

Parvovirus B19-specific antibodies were isolated using parvovirus B19 antigen-coated plates (Abcam1788650- AntiParvovirus B19 IgG ELISA, Cambridge, United Kingdom). Sera $(20 \mu \mathrm{l})$ were diluted in specimen diluent $(80 \mu \mathrm{l})$ from the kit and then incubated in the plates for 1 hour at room temperature (RT) with shaking. Positive and negative controls from the kit were used as controls. Washing and eluting specific antibodies was performed as described above for CMVspecific antibodies.

\section{Purification of anti-N and anti-S specific antibodies from plasma}

SARS-Cov-2-specific antibodies were purified using antigen-coated plates (NUNC, Roskilde, Denmark). Plates were coated overnight at $4^{\circ} \mathrm{C}$ with recombinant trimerized spike protein produced as described recently (34) or $\mathrm{N}$ protein [GenBank: MN908947, produced in HEK cells with a HAVT20 leader peptide, 10x His tag, and a BirA tag (24)] in PBS $(5 \mu \mathrm{g} / \mathrm{ml}$ and $1 \mu \mathrm{g} / \mathrm{ml}$, respectively). Plates were washed three times with PBS $(250 \mu \mathrm{l})$ supplemented with $0.05 \%$ TWEEN $20^{\circledR}($ PBS-T). Plasma $(20 \mu \mathrm{l})$ was diluted in PBS-T $(180 \mu \mathrm{l})$ and then incubated for 1 hour at room temperature (RT) with shaking. Sera dating pre COVID-19 pandemic were used as negative controls. The plates were washed three times with PBS-T $(250 \mu \mathrm{l})$, twice with PBS $(250 \mu \mathrm{l})$, and twice with $250 \mathrm{\mu l}$ ammonium bicarbonate $(50 \mathrm{mM})$. The bound antibodies were then eluted with $100 \mathrm{mM}$ formic acid $(200 \mu \mathrm{l})$.

\section{Purification of total IgG from sera}

Total IgG1 antibodies were captured from $2 \mu$ of serum using Protein G Sepharose 4 Fast Flow beads (GE Healthcare, Uppsala, Sweden) in a 96-well filter plate (Millipore Multiscreen, Amsterdam, The Netherlands) as previously described (12) or by using Protein G cartridges on the AssayMAP Bravo (Agilent Technologies, Santa Clara, USA). Briefly, $1 \mu \mathrm{l}$ of serum diluted in PBS was applied to the cartridges, followed by washes with PBS and LC-MS pure water. IgG antibodies were then eluted with $1 \%$ formic acid. 


\section{Mass spectrometric IgG-Fc glycosylation analysis}

Eluates containing either antigen-specific antibodies or total IgG were collected in V-bottom plates and dried by vacuum centrifugation for 2.5 hours at $50^{\circ} \mathrm{C}$. The HPAla, CMV, HIV, Parvovirus B19, HBV, and COVID-19 samples were then subjected to proteolytic cleavage using trypsin as described before (12). The measles and mumps cohort samples were dissolved in a buffer containing $0.4 \%$ sodium deoxycholate (SDC), $10 \mathrm{mM}$ TCEP, $40 \mathrm{mM}$ chloroacetamide, and $100 \mathrm{mM}$ TRIS pH 8.5. After a 10-min incubation at $95^{\circ} \mathrm{C}, 250 \mathrm{ng}$ of trypsin in $50 \mathrm{mM}$ ammonium bicarbonate was added. The digestion was stopped after an overnight incubation by acidifying to $2 \%$ formic acid. Prior to MS injection, SDC precipitates were removed by centrifuging samples at $20,000 \mathrm{~g}$ for $30 \mathrm{~min}$. Analysis of IgG Fc-glycosylation was performed with nanoLC reverse phase (RP)-electrospray (ESI)-MS on an Ultimate 3000 RSLCnano system (Dionex/Thermo Scientific, Breda, The Netherlands) coupled to an amaZon speed ion trap MS (Bruker Daltonics, Bremen, Germany) as described previously (12). Alternatively, the measles, mumps, and COVID-19 cohorts were measured on an ImpactHD quadrupole-time-offlight MS (Bruker Daltonics) as previously described (35). In the current study, we focused on IgG1, without analyzing IgG3 due to its possible interference with IgG2 and IgG4 at the glycopeptide level (36). Mass spectrometry results were extracted and evaluated using DataAnalysis software (version 5.0; Bruker Daltonics) for all samples except for the measles, mumps, and COVID-19 cohorts that were analyzed with Skyline software (version 4.2.19107). Data was judged reliable when the sum of the signal intensities of all glycopeptide species (table S3) was higher than negative samples plus 10 times its standard division. Otherwise, the data was excluded (12). The total level of glycan traits was calculated as described in table S4.

\section{Cytokine release assay}

Monocytes were isolated from buffy coats and differentiated as previously described (37) using M-CSF and IL-10. This results in a phenotype resembling alveolar macrophage-like monocyte-derived macrophages $(37,38)$. To generated IgG immune complexes, $2 \mu \mathrm{g} / \mathrm{ml}$ of glycoengineered IgG1 (39) was coated overnight in PBS on a 96-well high-affinity plate (Nunc; Roskilde; Denmark). Macrophages (50,000/well) were stimulated in pre-coated plates as described in legend in combination with $20 \mu \mathrm{g} / \mathrm{ml}$ of poly(I:C) (Sigma-Aldrich). To measure IL-6 production, supernatants were harvested after 24 hours of stimulation. IL-6 was then detected using an IL-6 ELISA kit according to the manufacturer's instructions (U-CyTech Biosciences). Both coating and detection antibodies were diluted 1:200.

\section{Meso Scale Discovery multiplex assay}

V-PLEX Custom Human Cytokine10-plex kit was purchased from Mesoscale Discovery (MSD). The lyophilized cocktail mix calibrators were reconstituted in provided assay diluents respectively. Plasma and sera $(10 \mu \mathrm{l})$ were diluted in $40 \mu \mathrm{l}$ MSD Sample Diluent for IL-6 measurement. The assay was performed according to the manufacturer's instructions with an overnight incubation of the diluted samples and standards at $4^{\circ} \mathrm{C}$. The electrochemiluminescence signal (ECL) was detected by MESO QuickPlex SQ 120 plate reader (MSD) and analyzed with Discovery Workbench Software (v4.0, MSD).

\section{Anti-SARS-CoV2 antibody levels}

Antibody levels were quantified by ELISA. Briefly, samples were tested at 100-1200-fold dilutions in PBS supplemented with $0.1 \%$ polysorbate- 20 and $0.3 \%$ gelatin (PTG) in microtiter plates coated with $\mathrm{S}$ or N-protein and incubated for 1 hour at RT. Both proteins were produced as previously described (26). After washing, $0.5 \mu \mathrm{g} / \mathrm{ml}$ of HRP-conjugated anti-human IgG (MH16-1, Sanquin) was added in PTG and incubated for 1 hour at RT. Following enzymatic conversion of TMB substrate, absorbance was measured at $450 \mathrm{~nm}$ and $540 \mathrm{~nm}$. Antibody binding was evaluated by comparison to a reference plasma pool of convalescent COVID-19 patients set at $100 \mathrm{AU} / \mathrm{ml}$.

\section{Statistical analysis}

Statistical analyses were performed using GraphPad Prism (version 8.0.2) for Windows (GraphPad Software Inc., La Jolla, CA, www.graphpad.com). To analyze whether Fc-fucosylation for total and antigen specific IgG differs between the tested cohorts, statistical analysis was performed using two-way ANOVA and paired $t$ tests as specified for the individual cohorts. The same tests were used for comparing cytokine release from stimulated macrophages. To investigate whether Fc-fucosylation profiles of two specific antibodies in the same individual were correlated, statistical analysis was performed using a Pearson's correlation. A Pearson's correlation was also used to test the correlation between Fc-fucosylation of anti-S and anti-N IgG. To test correlations between cytokine release and IgG Fc-fucosylation, as well as between the degree of anti-S Fc fucosylation and CRP levels, a Spearman's correlation was performed. Only statistically significant differences are shown. ${ }^{*} P<0.05,{ }^{* *} P<0.01,{ }^{* * *} P<0.001$, $* * * * P<0.0001$. 


\section{REFERENCES AND NOTES}

1. M. H. C. Biermann, G. Griffante, M. J. Podolska, S. Boeltz, J. Stürmer, L. E. Muñoz, R. Bilyy, M. Herrmann, Sweet but dangerous - the role of immunoglobulin G glycosylation in autoimmunity and inflammation. Lupus 25, 934-942 (2016). doi:10.1177/0961203316640368 Medline

2. R. Jefferis, Glycosylation as a strategy to improve antibody-based therapeutics. Nat. Rev. Drug Discov. 8, 226-234 (2009). doi:10.1038/nrd2804 Medline

3. G. Vidarsson, G. Dekkers, T. Rispens, IgG subclasses and allotypes: From structure to effector functions. Front. Immunol. 5, 520 (2014). doi:10.3389/fimmu.2014.00520 Medline

4. G. Dekkers, T. Rispens, G. Vidarsson, Novel concepts of altered immunoglobulin G galactosylation in autoimmune diseases. Front. Immunol. 9, 553 (2018). doi:10.3389/fimmu.2018.00553 Medline

5. R. L. Shields, J. Lai, R. Keck, L. Y. O'Connell, K. Hong, Y. G. Meng, S. H. A. Weikert, L. G. Presta, Lack of fucose on human IgG1 N-linked oligosaccharide improves binding to human Fcgamma RIII and antibody-dependent cellular toxicity. J. Biol. Chem. 277, 26733-26740 (2002). doi:10.1074/jbc.M202069200 Medline

6. C. Ferrara, S. Grau, C. Jäger, P. Sondermann, P. Brünker, I. Waldhauer, M. Hennig, A. Ruf, A. C. Rufer, M. Stihle, P. Umaña, J. Benz, Unique carbohydratecarbohydrate interactions are required for high affinity binding between FcgammaRIII and antibodies lacking core fucose. Proc. Natl. Acad. Sci. U.S.A. 108, 12669-12674 (2011). doi:10.1073/pnas.1108455108 Medline

7. J. M. Reichert, Antibodies to watch in 2016. MAbs 8, 197-204 (2016). do::10.1080/19420862.2015.1125583 Medline

8. M. P. Baković, M. H. J. Selman, M. Hoffmann, I. Rudan, H. Campbell, A. M. Deelder, G. Lauc, M. Wuhrer, High-throughput IgG Fc N-glycosylation profiling by mass spectrometry of glycopeptides. J. Proteome Res. 12, 821-831 (2013). doi:10.1021/pr300887z Medline

9. N. de Haan, K. R. Reiding, G. Driessen, M. van der Burg, M. Wuhrer, Changes in healthy human IgG Fc-glycosylation after birth and during early childhood. $J$. Proteome Res. 15, 1853-1861 (2016). doi:10.1021/acs.jproteome.6b00038 Medline

10. X. Yu, Y. Wang, J. Kristic, J. Dong, X. Chu, S. Ge, H. Wang, H. Fang, Q. Gao, D. Liu, Z. Zhao, H. Peng, M. Pucic Bakovic, L. Wu, M. Song, I. Rudan, H. Campbell, G. Lauc, W. Wang, Profiling IgG N-glycans as potential biomarker of chronological and biological ages: A community-based study in a Han Chinese population. Medicine (Baltimore) 95, e4112 (2016). doi:10.1097/MD.0000000000004112 Medline

11. M. Wuhrer, L. Porcelijn, R. Kapur, C. A. M. Koeleman, A. Deelder, M. de Haas, G. Vidarsson, Regulated glycosylation patterns of IgG during alloimmune responses against human platelet antigens. J. Proteome Res. 8, 450-456 (2009). doi:10.1021/pr80065lj Medline

12. R. Kapur, I. Kustiawan, A. Vestrheim, C. A. M. M. Koeleman, R. Visser, H. K. Einarsdottir, L. Porcelijn, D. Jackson, B. Kumpel, A. M. Deelder, D. Blank, B. Skogen, M. K. Killie, T. E. Michaelsen, M. de Haas, T. Rispens, C. E. van der Schoot M. Wuhrer, G. Vidarsson, A prominent lack of IgG1-Fc fucosylation of platelet alloantibodies in pregnancy. Blood 123, 471-480 (2014). doi:10.1182/blood-201309-527978 Medline

13. R. Kapur, L. Della Valle, M. Sonneveld, A. Hipgrave Ederveen, R. Visser, P. Ligthart, M. de Haas, M. Wuhrer, C. E. van der Schoot, G. Vidarsson, Low anti-RhD IgG-FCfucosylation in pregnancy: A new variable predicting severity in haemolytic disease of the fetus and newborn. Br. J. Haematol. 166, 936-945 (2014). doi:10.1111/bjh. 12965 Medline

14. M. E. Sonneveld, S. Natunen, S. Sainio, C. A. M. Koeleman, S. Holst, G. Dekkers, J. Koelewijn, J. Partanen, C. E. van der Schoot, M. Wuhrer, G. Vidarsson, Glycosylation pattern of anti-platelet IgG is stable during pregnancy and predicts clinical outcome in alloimmune thrombocytopenia. Br. J. Haematol. 174, 310-320 (2016). doi:10.1111/bih.14053 Medline

15. T. T. Wang, J. Sewatanon, M. J. Memoli, J. Wrammert, S. Bournazos, S. K. Bhaumik, B. A. Pinsky, K. Chokephaibulkit, N. Onlamoon, K. Pattanapanyasat, J. K. Taubenberger, R. Ahmed, J. V. Ravetch, IgG antibodies to dengue enhanced for FçRIIIA binding determine disease severity. Science 355, 395-398 (2017). doi:10.1126/science.aai8128 Medline
16. M. E. Ackerman, M. Crispin, X. Yu, K. Baruah, A. W. Boesch, D. J. Harvey, A.-S. S. Dugast, E. L. Heizen, A. Ercan, I. Choi, H. Streeck, P. A. Nigrovic, C. Bailey-Kellogg, C. Scanlan, G. Alter, Natural variation in Fc glycosylation of HIV-specific antibodies impacts antiviral activity. J. Clin. Invest. 123, 2183-2192 (2013). doi:10.1172/JCl65708 Medline

17. M. E. Sonneveld, J. Koelewijn, M. de Haas, J. Admiraal, R. Plomp, C. A. M. Koeleman, A. L. Hipgrave Ederveen, P. Ligthart, M. Wuhrer, C. E. van der Schoot, G. Vidarsson, Antigen specificity determines anti-red blood cell lgG-Fc alloantibody glycosylation and thereby severity of haemolytic disease of the fetus and newborn. Br. J. Haematol. 176, 651-660 (2017). doi:10.1111/bih.14438 Medline

18. M. H. J. Selman, S. E. de Jong, D. Soonawala, F. P. Kroon, A. A. Adegnika, A. M. Deelder, C. H. Hokke, M. Yazdanbakhsh, M. Wuhrer, Changes in antigen-specific IgG1 Fc N-glycosylation upon influenza and tetanus vaccination. Mol. Cell. Proteomics 11, 014563 (2012). doi:10.1074/mcp.M111.014563 Medline

19. J. Krištić, F. Vučković, C. Menni, L. Klarić, T. Keser, I. Beceheli, M. Pučić-Baković, M. Novokmet, M. Mangino, K. Thaqi, P. Rudan, N. Novokmet, J. Sarac, S. Missoni, I. Kolčić, O. Polašek, I. Rudan, H. Campbell, C. Hayward, Y. Aulchenko, A. Valdes, J. F. Wilson, O. Gornik, D. Primorac, V. Zoldoš, T. Spector, G. Lauc, Glycans are a novel biomarker of chronological and biological ages. J. Gerontol. A Biol. Sci. Med. Sci. 69, 779-789 (2014). doi:10.1093/gerona/glt190 Medline

20. L. Bouadma, F. X. Lescure, J. C. Lucet, Y. Yazdanpanah, J. F. Timsit, Severe SARSCoV-2 infections: Practical considerations and management strategy for intensivists. Intensive Care Med. 46, 579-582 (2020). doi:10.1007/s00134-02005967-x Medline

21. C. Huang, Y. Wang, X. Li, L. Ren, J. Zhao, Y. Hu, L. Zhang, G. Fan, J. Xu, X. Gu, Z. Cheng, T. Yu, J. Xia, Y. Wei, W. Wu, X. Xie, W. Yin, H. Li, M. Liu, Y. Xiao, H. Gao, L. Guo, J. Xie, G. Wang, R. Jiang, Z. Gao, Q. Jin, J. Wang, B. Cao, Clinical features of patients infected with 2019 novel coronavirus in Wuhan, China. Lancet 395, 497506 (2020). doi:10.1016/S0140-6736(20)30183-5 Medline

22. C. Ceraolo, F. M. Giorgi, Genomic variance of the 2019-nCoV coronavirus. J. Med. Virol. 92, 522-528 (2020). doi:10.1002/imv.25700 Medline

23. T. T. Wang, J. Maamary, G. S. Tan, S. Bournazos, C. W. Davis, F. Krammer, S. J. Schlesinger, P. Palese, R. Ahmed, J. V. Ravetch, Anti-HA Glycoforms Drive B Cell Affinity Selection and Determine Influenza Vaccine Efficacy. Cell 162, 160-169 (2015). doi:10.1016/i.cell.2015.06.026 Medline

24. G. Dekkers, L. Treffers, R. Plomp, A. E. H. Bentlage, M. de Boer, C. A. M. Koeleman, S. N. Lissenberg-Thunnissen, R. Visser, M. Brouwer, J. Y. Mok, H. Matlung, T. K. van den Berg, W. J. E. van Esch, T. W. Kuijpers, D. Wouters, T. Rispens, M. Wuhrer, G. Vidarsson, Decoding the human immunoglobulin G-glycan repertoire reveals a spectrum of Fc-receptor- and complement-mediated-effector activities. Front. Immunol. 8, 877 (2017). doi:10.3389/fimmu.2017.00877 Medline

25. A. R. Temming, S. W. de Taeye, E. L. de Graaf, L. A. de Neef, G. Dekkers, C. W. Bruggeman, J. Koers, P. Ligthart, S. Q. Nagelkerke, J. C. Zimring, T. W. Kuijpers, M. Wuhrer, T. Rispens, G. Vidarsson, Functional Attributes of Antibodies, Effector Cells, and Target Cells Affecting NK Cell-Mediated Antibody-Dependent Cellular Cytotoxicity. J. Immunol. 203, 3126-3135 (2019). doi:10.4049/iimmunol.1900985 Medline

26. E. H. Vogelzang, F. C. Loeff, N. I. L. Derksen, S. Kruithof, P. Ooijevaar-de Heer, G. van Mierlo, F. Linty, J. Y. Mok, W. van Esch, S. de Bruin, A. P. J. Vlaar, B. Seppen, M. Leeuw, A. J. G. van Oudheusden, A. G. M. Buiting, K. K. Jim, H. Vrielink, F. Swaneveld, G. Vidarsson, C. E. van der Schoot, P. C. Wever, W. Li, F. van Kuppeveld, J.-L. Murk, B. J. Bosch, G.-J. J. Wolbink, T. Rispens; Amsterdam University Medical Center COVID-19 Biobank Study Group, Development of a SARS-CoV-2 Total Antibody Assay and the Dynamics of Antibody Response over Time in Hospitalized and Nonhospitalized Patients with COVID-19. J. Immunol. 205, 3491-3499 (2020). doi:10.4049/jimmunol.2000767 Medline

27. R. Kapur, L. Della Valle, O. J. H. M. Verhagen, A. Hipgrave Ederveen, P. Ligthart, M. de Haas, B. Kumpel, M. Wuhrer, C. E. van der Schoot, G. Vidarsson, Prophylactic anti-D preparations display variable decreases in Fc-fucosylation of anti-D. Transfusion 55, 553-562 (2015). doi:10.1111/trf.12880 Medline

28. N. L. Bernasconi, E. Traggiai, A. Lanzavecchia, Maintenance of serological memory by polyclonal activation of human memory B cells. Science 298, 2199-2202 (2002). doi:10.1126/science.1076071 Medline 
29. M. W. N. Nijsten, E. R. de Groot, H. J. ten Duis, H. J. Klasen, C. E. Hack, L. A. Aarden, Serum levels of interleukin-6 and acute phase responses. Lancet 2, 921 (1987). doi:10.1016/S0140-6736(87)91413-9 Medline

30. A. Volz, G. Sutter, Modified Vaccinia Virus Ankara: History, Value in Basic Research, and Current Perspectives for Vaccine Development. Adv. Virus Res. 97 187-243 (2017). doi:10.1016/bs.aivir.2016.07.001 Medline

31. L. Liu, Q. Wei, Q. Lin, J. Fang, H. Wang, H. Kwok, H. Tang, K. Nishiura, J. Peng, Z. Tan, T. Wu, K. W. Cheung, K. H. Chan, X. Alvarez, C. Qin, A. Lackner, S. Perlman, K. Y. Yuen, Z. Chen, Anti-spike IgG causes severe acute lung injury by skewing macrophage responses during acute SARS-CoV infection. JCI Insight 4, e123158 (2019). doi:10.1172/jci.insight.123158 Medline

32. B. Quinlan, H. Mou, L. Zhang, Y. Guo, W. He, A. Ojha, M. Parcells, G. Luo, W. Li, G. Zhong, H. Choe, M. Farzan, bioRxiv 036418 [Preprint]. 12 April 2020. https://doi.org/10.1101/2020.04.10.036418.

33. Q. Ye, B. Wang, J. Mao, The pathogenesis and treatment of the 'Cytokine Storm' in COVID-19. J. Infect. 80, 607-613 (2020). doi:10.1016/i.jinf.2020.03.037 Medline

34. P. J. M. Brouwer, T. G. Caniels, K. van der Straten, J. L. Snitselaar, Y. Aldon, S. Bangaru, J. L. Torres, N. M. A. Okba, M. Claireaux, G. Kerster, A. E. H. Bentlage, M. M. van Haaren, D. Guerra, J. A. Burger, E. E. Schermer, K. D. Verheul, N. van der Velde, A. van der Kooi, J. van Schooten, M. J. van Breemen, T. P. L. Bijl, K. Sliepen, A. Aartse, R. Derking, I. Bontjer, N. A. Kootstra, W. J. Wiersinga, G. Vidarsson, B. L. Haagmans, A. B. Ward, G. J. de Bree, R. W. Sanders, M. J. van Gils, Potent neutralizing antibodies from COVID-19 patients define multiple targets of vulnerability. Science 369, 643-650 (2020). doi:10.1126/science.abc5902 Medline

35. D. Falck, B. C. Jansen, N. de Haan, M. Wuhrer, High-Throughput Analysis of IgG Fc Glycopeptides by LC-MS. Methods Mol. Biol. 1503, 31-47 (2017). doi:10.1007/978-1-4939-6493-2 4 Medline

36. M. Wuhrer, J. C. Stam, F. E. van de Geijn, C. A. M. Koeleman, C. T. Verrips, R. J. E. M. Dolhain, C. H. Hokke, A. M. Deelder, Glycosylation profiling of immunoglobulin G (IgG) subclasses from human serum. Proteomics 7, 4070-4081 (2007). doi:10.1002/pmic.200700289 Medline

37. W. Hoepel, H.-J. Chen, S. Allahverdiyeva, X. Manz, J. Aman, A. U. C.-19 Biobank, P. Bonta, P. Brouwer, S. de Taeye, T. Caniels, K. van der Straten, K. Golebski, G. Griffith, R. Jonkers, M. Larsen, F. Linty, A. Neele, J. Nouta, F. van Baarle, C. van Drunen, A. Vlaar, G. de Bree, R. Sanders, L. Willemsen, M. Wuhrer, H. J. Bogaard, M. van Gils, G. Vidarsson, M. de Winther, J. den Dunnen, Anti-SARS-CoV-2 IgG from severely ill COVID-19 patients promotes macrophage hyper-inflammatory responses. bioRxiv (2020). 10.1101/2020.07.13.190140

38. H. J. Chen, A. Y. F. Li Yim, G. R. Griffith, W. J. de Jonge, M. M. A. M. Mannens, E. Ferrero, P. Henneman, M. P. J. de Winther, Meta-Analysis of in vitro-Differentiated Macrophages Identifies Transcriptomic Signatures That Classify Disease Macrophages in vivo. Front. Immunol. 10, 2887 (2019). doi:10.3389/fimmu.2019.02887 Medline

39. G. Dekkers, R. Plomp, C. A. M. Koeleman, R. Visser, H. H. von Horsten, V. Sandig, T. Rispens, M. Wuhrer, G. Vidarsson, Multi-level glyco-engineering techniques to generate IgG with defined Fc-glycans. Sci. Rep. 6, 36964 (2016). doi:10.1038/srep36964 Medline

\section{ACKNOWLEDGMENTS}

We thank Prof. Dr. R.J.M. ten Berge for helpful discussions. The Amsterdam Cohort Studies on HIV infection and AIDS, is a collaboration between the Amsterdam Health Service, the Academic Medical Centre of the University of Amsterdam and Sanquin Blood Supply Foundation. The ACS is part of the Netherlands HIV Monitoring Foundation and financially supported by the Netherlands National Institute for Public Health and the Environment. We are greatly indebted to all cohort participants for their continuous participation. Funding: This work was supported by LSBR grants number 1229 and 1908 (to G.V.) and by the European Union (Seventh Framework Programme HighGlycan project, grant number 278535 and H2020 project GlySign, grant number 722095), by Marie Skłodowska-Curie grant grant 847551 . (to JdD), by the Netherlands Organization for Scientific Research (NWO) Vici grant (to R.W.S.), by ZonMW COVID-19 grants 10430012010008 (to JdD) and 10430012010021 (to G.V.), and from COVID19 grants from the Amsterdam Infection and Immunity Institute no 24184 (to $\mathrm{JdD}$ ) and 24175 (to MvG).Author contributions: All samples were collected by S.N., S.S., S.T., A.V., A.B., R.V., M.L., M.B., T.S., S.dB., F.L., N.K., H.Z., G.W. and M.S. M.S., C.K., R.P., J.N., M.L., and E.dG. performed antibody purifications, mass spectrometric analyses and data processing. F.L., M.B., T.S., and P.B. generated recombinant antigens. N.D. performed anti-COVID-19 ELISAs. M.S., E.dG., M.L., S.dB., A.V., G.V., and E.vdS. analyzed clinical data and performed data analysis. W.H. and C.E.G. performed macrophage stimulation experiments and cytokine ELISAs. H.J.C. performed MSD experiments and analysis. M.L., M.S., E.dG., M.W., and G.V. generated figures and tables. M.vG., M.dW., J.dD., T.R., R.S., E.vdS., M.W., and G.V. supervised the study. All authors contributed to analysis and interpretation of the data. M.L., M.S., E.dG., E.S., M.W., and G.V. wrote the paper, which was critically revised and approved by all authors. Competing interests: The authors declare no competing interest. Data and materials availability: All data are available in the manuscript or supplementary materials. This work is licensed under a Creative Commons Attribution 4.0 International (CC BY 4.0) license, which permits unrestricted use, distribution, and reproduction in any medium, provided the original work is properly cited. To view a copy of this license, visit

https://creativecommons.org/licenses/by/4.0/. This license does not apply to figures/photos/artwork or other content included in the article that is credited to a third party; obtain authorization from the rights holder before using such material.

\section{SUPPLEMENTARY MATERIALS}

science.sciencemag.org/cgi/content/full/science.abc8378/DC1

Figs. S1 to S15

Tables S1 to S4

Amsterdam UMC COVID-19 biobank study group

MDAR Reproducibility Checklist

16 May 2020; resubmitted 12 October 2020

Accepted 18 December 2020

Published online 23 December 2020

$10.1126 /$ science.abc8378 
A
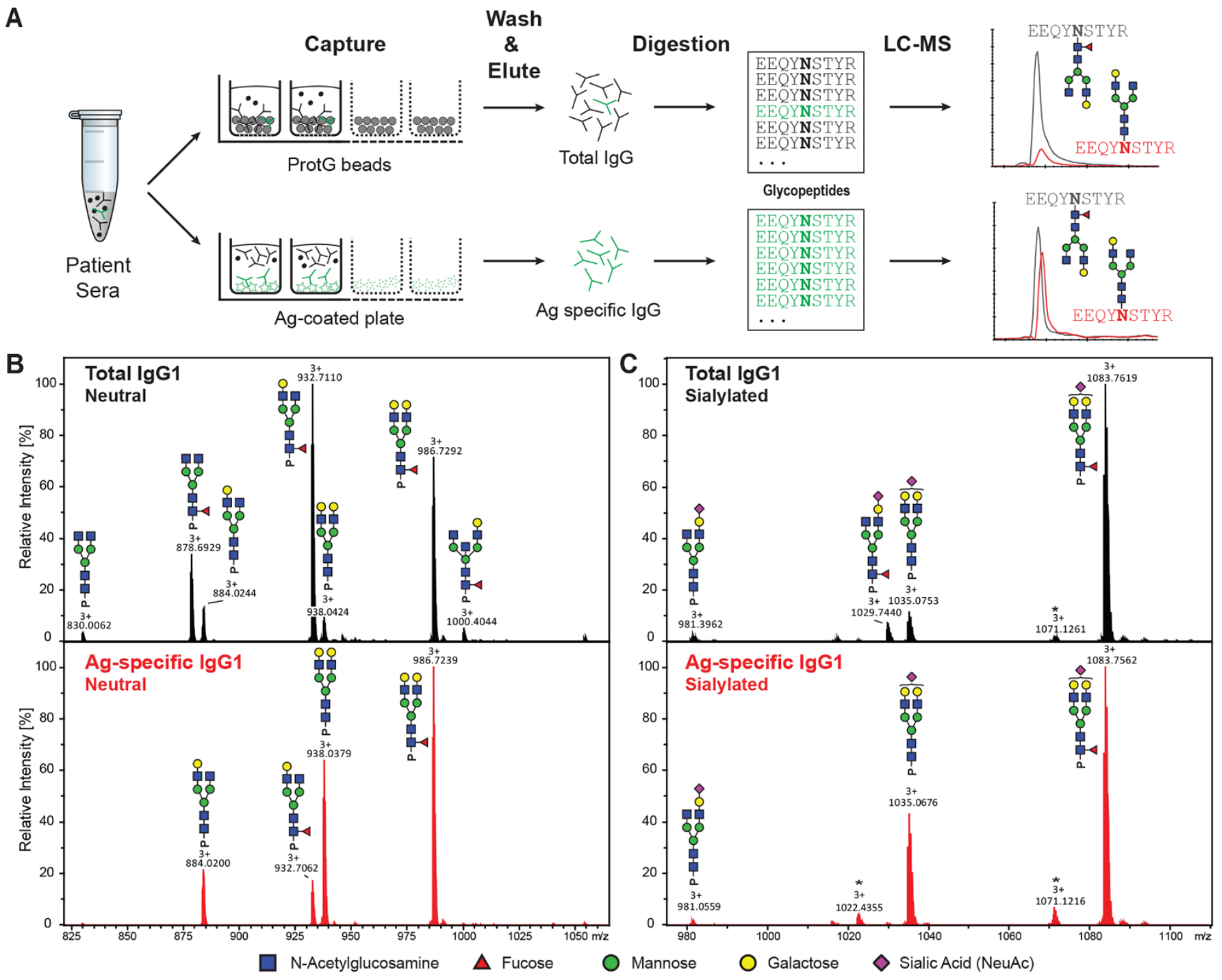

Fig. 1. Flowchart of antibody-specific IgG1 glycosylation analysis by mass spectrometry. (A) Antibodies were captured from sera using Protein $G$ beads and antigen-coated 96-well plates resulting in total and antigen-specific IgG fractions, respectively. Thereafter, isolated IgG were digested with trypsin and the resulting glycopeptides were analyzed by nano liquid chromatography-mass spectrometry. (B and $C$ ) Representative mass spectra of glycopeptides encompassing the Fc glycosylation site Asn297. Neutral (B) and sialylated (C) IgG1 glycopeptides are shown from a single patient's total (upper panel, in black) and antigen-specific (lower panel, in red) IgG1 fraction. Asterisks indicate non-Fc glycopeptides. 

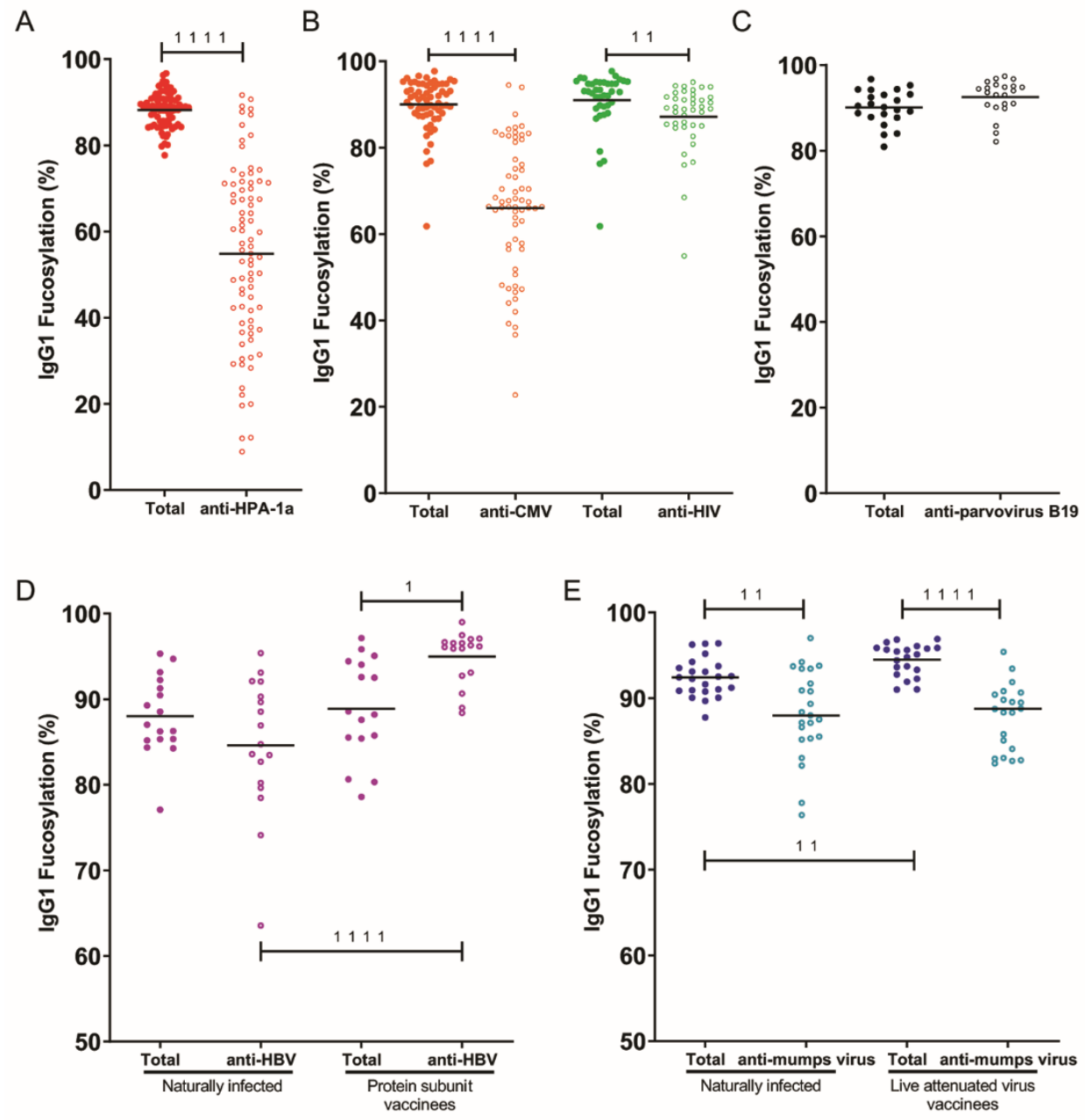

Fig. 2. Foreign membrane protein antigens, such as envelope proteins of (attenuated) enveloped viruses or alloantigens can trigger afucosylated IgG responses. IgG1-Fc fucosylation levels of total (filled circles) and antigen-specific (open circles) antibodies are shown for each differently color-coded group of antigens: (A) alloantigen HPA-1a; (B) viral envelope antigens from CMV and HIV; (C) non-enveloped viral antigens from parvovirus B19; (D) $\mathrm{HBsAg}$ - in individuals naturally infected with HBV (left) or vaccinated with recombinant soluble HBsAg (right); and (E) mumps virus antigens in individuals naturally infected with mumps virus (left) or vaccinated with live attenuated mumps virus (right). Each circle represents a biological replicate $[n=80$ for anti-HPA-1a (A), $n=65$ for CMV and $n=40$ for HIV (B), $n=22$ for B19 (C), $n=17$ for naturally infected individuals for HBV and $n=17$ for HBV vaccinated individuals (D) and $n=24$ naturally infected individuals for mumps virus and $n=21$ for mumps vaccinated individuals (E)] of a representative LC-MS run (examples of technical replicates in fig.S1C). Statistical analyses were performed as paired $t$ tests for $(A)$, (B), and (C) and a mixed model twoway ANOVA with Bonferroni correction of post hoc $t$ tests for comparing Fc fucosylation between groups for (D) and (E). Only statistically significant differences are shown. ${ }^{*} P<0.05$, ${ }^{*} P<0.01$, ${ }^{* *} P<0.001$, and ${ }^{* * * *} P<0.0001$. 


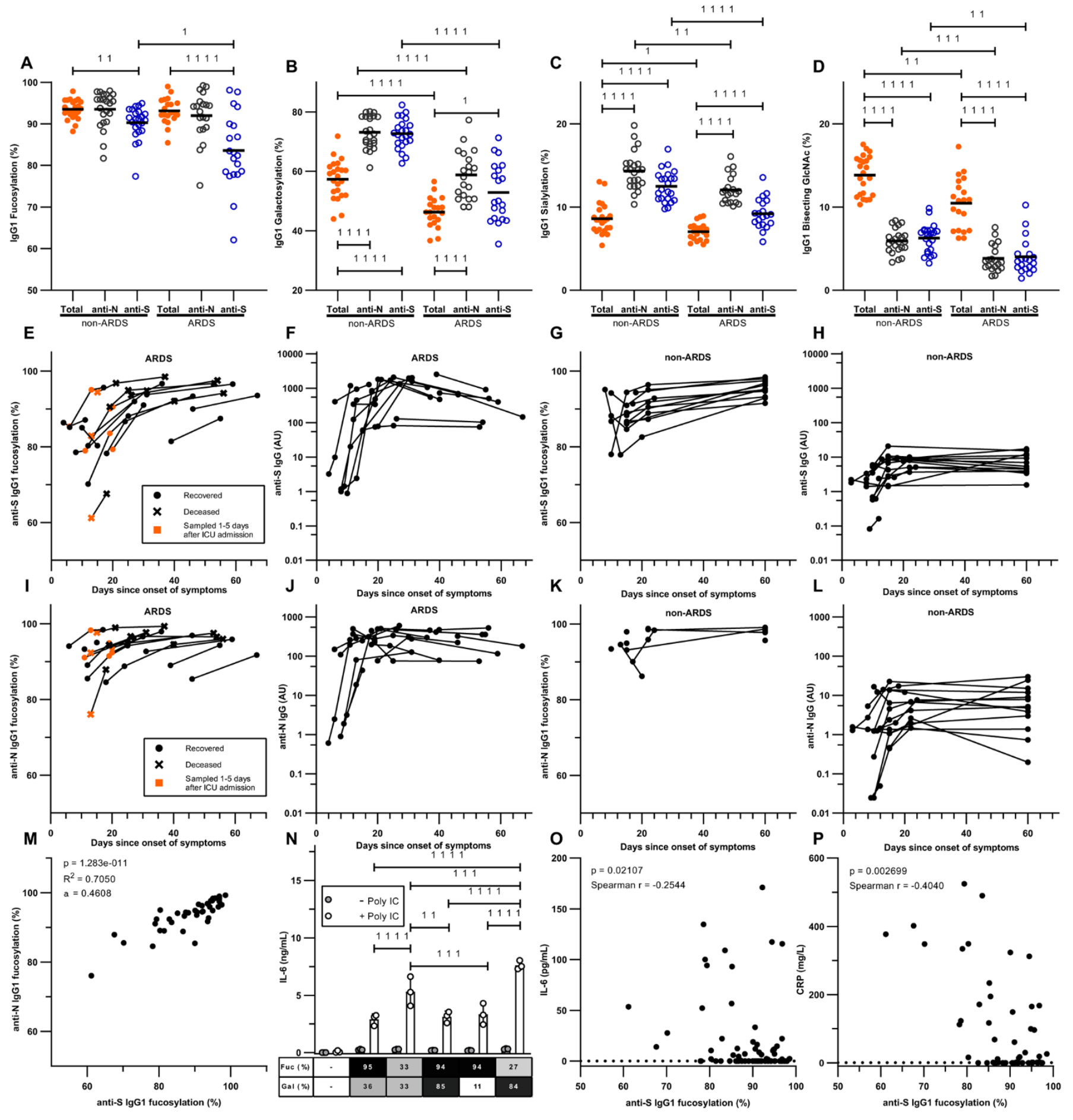


Fig. 3. Fc fucosylation levels of anti-S IgG1 are significantly decreased in critically ill COVID-19 patients. (A) Fc fucosylation, (B) galactosylation, (C) sialylation, and (D) bisection degree of anti-S, anti-N, and total IgG1 from ARDS patients and non-ARDS donors clearing the infection asymptomatically or with mild symptoms from the initial screen. (E to L) Longitudinal lgG1-Fc fucosylation and IgG quantity for anti-S [(E) to $(H)]$ and anti-N $[(I)$ to $(L)]$ in ARDS patients $[(E),(F),(I)$, and $(J)]$ and in non-ARDS cases $[(G),(H),(K)$, and $(\mathrm{L})$ ]. (M) Correlation between anti-N and anti-S IgG1-Fc fucosylation. (N) Representative examples of IL-6 release from macrophages triggered through $\mathrm{F} c \gamma R$ - by stimulation with glycoengineered IgG-complexes with or without poly(I:C). (O) Correlation between plasma IL-6 levels and degrees of anti-S IgG1-Fc fucosylation. (P) Correlation between plasma CRP levels and degrees of anti-S IgG1-Fc fucosylation. Each circle represents a biological replicate ( $n=20$ for ARDS, $n=23$ for non-ARDS [(A) to (D)], $n=17$ and $n=14$ for longitudinal ARDS and non-ARDS, respectively [(E) to (L)]. Examples of technical replicates for LC-MS data are shown in fig.S1C. IgG data $[(F),(H),(J)$, and $(L)]$ are representative ELISA values calibrated against a standard pool from two technical experiments. All available paired data used in $(\mathrm{M})(n=40)$. IL-6 production by macrophages were measured by ELISA with each dot $(n=3)$ representing a technical replicate $(\mathrm{N})$. All six biological replicates are shown in fig. S13. CRP and IL-6 levels were obtained from clinical parameters and IL6 data by Mesoscale Discovery using all available paired data $[n=82(O)$ and $n=53(P)]$. Statistical analyses were performed as a mixed model two-way ANOVA with Bonferroni correction of post hoc $t$ tests for comparing glycosylation traits and cytokine secretion between groups. Spearman's correlations were performed in $(O)$ to $(P)$. To test the correlation between $\mathrm{Fc}$ fucosylation levels for anti-S and anti-N, a Pearson's correlation was performed. Only statistically significant differences are shown. ${ }^{*} P<0.05,{ }^{*} P<$ $0.01,{ }^{* *} P<0.001,{ }^{* * *} P<0.0001$. 


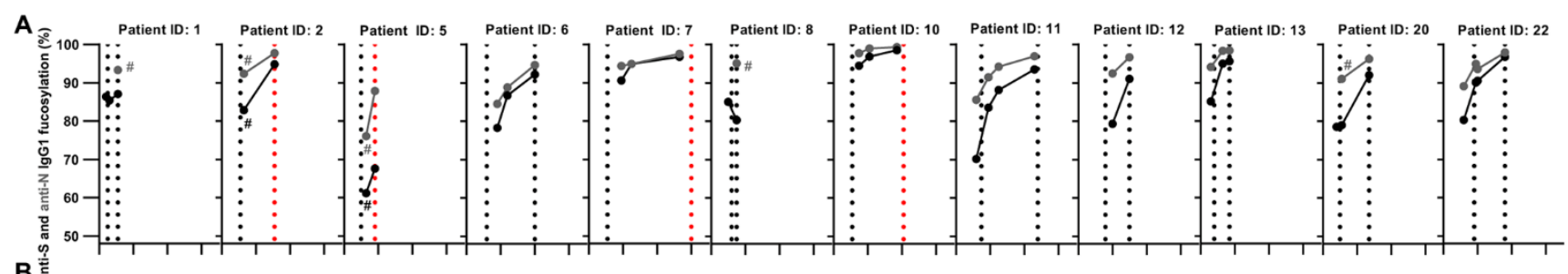

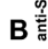
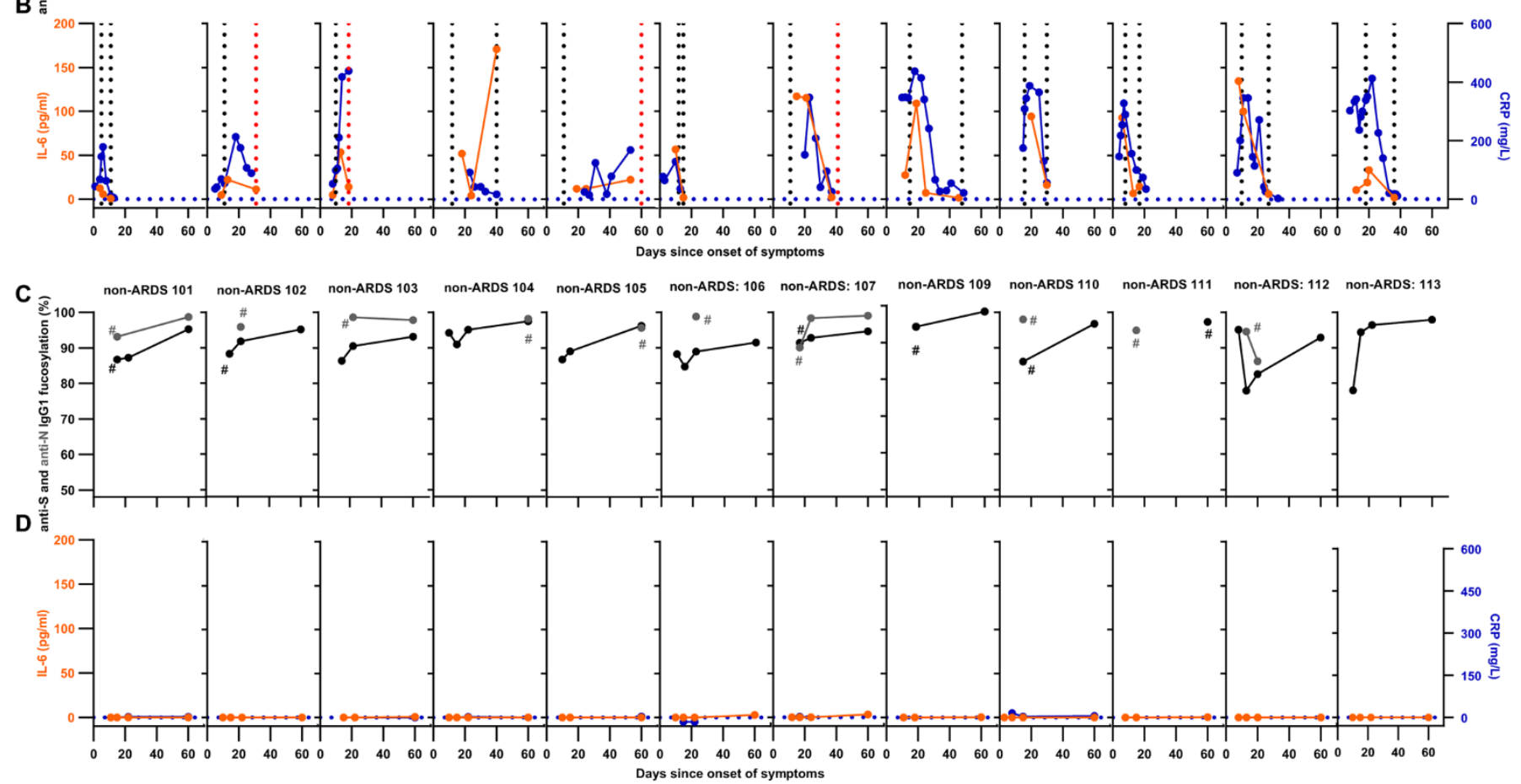

Fig. 4. Longitudinal changes of anti-SARS-CoV-2 IgG1 Fc fucosylation, CRP and IL-6. (A and C) Anti-S IgG fucosylation and anti-N IgG fucosylation and (B and D) IL-6 and CRP levels in an ARDS cohort $[(A)$ and (B)] and a non-ARDS cohort $[(C)$ and $(D)]$. Each panel represents longitudinal biological replicates of a LC-MS run [(A) and (C), examples of technical replicates in fig.S1C)], CRP obtained from clinical parameters, and IL-6 data using a validated Mesoscale Discovery assay [(B) and (D) ( $n=12$ for ARDS and $n=14$ for non-ARDS, with 2 to 16 longitudinal replicates per patient as indicated]. See fig. S15 for additional non-ARDS samples. Hash signs denote samples prior to these points were below the limit of detection for IgG1-glycosylation analyses. Vertical dotted lines in (A) and (B) represent the time of ICU admission and ICU discharge (black) or death (red), whereas dotted horizontal lines in (B) and (D) represent IL-6 and CRP detection limits. 

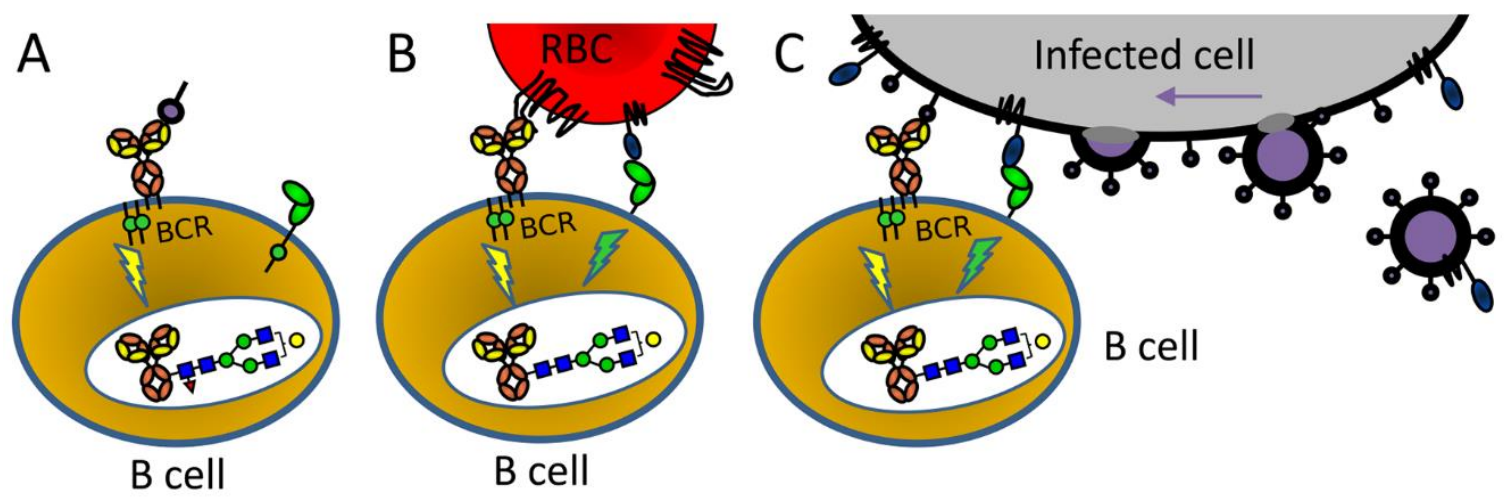

$B$ cell

९ viral antigen MDd Allo-antigen

N Self/Co-signal

\$ Self/Co-signal Receptor

Fig. 5. Hypothetical model explaining how different antigen contexts could produce altered immune signaling that gives rise to altered IgG glycosylation. (A) Immune responses to soluble protein antigen: $B$ cell receptor (BCR, a membrane immunoglobulin) is activated, resulting in the production of normal fucosylated antibodies. (B) For immune responses to alloantigens, paternal alloantigens on a red blood cell (RBC) are recognized by the BCR and possibly by other undescribed immune regulatory receptor-ligand pair(s) that provide a signal for recognition of self. (C) For immune responses to enveloped viral infection and attenuated viruses, the recognition of enveloped virus-infected cells by B cells would be similar as for the recognition of cellular alloantigens $(B)$. The initial recognition may potentially occur toward enveloped virus-infected cells and/or following viral assembly (far right). The proposed signaling in (B) and (C) causes altered glyco-programming of the B cells culminating in a unique IgG response characterized by a low Fc fucosylation (red triangle $=$ fucose) and enhanced ADCC. This model potentially explains both why immune responses to soluble proteins, non-enveloped viruses, and cellular pathogens such as bacteria are different from responses to enveloped viruses (and attenuated viruses). Furthermore, it may explain why immune responses to alloantigens immunologically resemble those of enveloped viral infections. 